\title{
Enhancing Socio-technical Governance: Targeting Inequality in Innovation through Inclusivity Mainstreaming
}

By Logan D. A. Williams ${ }^{a}$ and Thomas S. Woodson ${ }^{b}$

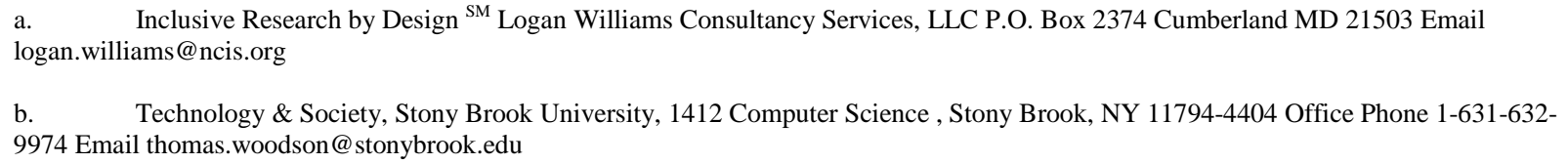

\section{ABSTRACT}

Socio-technical governance has been of long-standing interest to science and technology studies and science policy studies. Recent calls for midstream modulation direct attention to a more complicated model of innovation, and a new place for social scientists to intervene in research, design and development. This paper develops and expands this earlier work to demonstrate how a suite of concepts from science and technology studies and innovation studies can be used as a heuristic tool to conduct realtime evaluation and reflection during the process of innovation - upstream, midstream, and downstream. The result of this new protocol is inclusivity mainstreaming: determining if, and how, marginalized peoples (and perspectives) are being maximally incorporated into the model of innovation, while highlighting common problems of inequality that need to be addressed.

\section{Keywords}

poverty, inequality, innovation, inclusivity mainstreaming, policy, evaluation and reflection

\section{ACKNOWLEDGEMENTS}

Logan Williams thanks NSF DDIG 1153308, the CAORC Multi-country Fellowship, Rensselaer Polytechnic Institute, and Michigan State University for the funding that allowed her to collect the data about Aurolab and Tilganga-FHIOL from 2011-2012 and in 2017. Both authors thank David J. Hess, and two anonymous referees for their comments on an early draft. 


\section{INTRODUCTION}

Socio-technical governance today produces inequality: extreme wealth inequality between CEOs versus consumers (Peetz 2015); design inequality between white men and other social identities using information and communications devices (Oudshoorn, Rommes and Stienstra 2004; Pierce 2009; Roth 2013); health inequality between white men and other social identities with medical care needs (Read and Gorman 2010; Hoffman et al. 2016). Unfortunately, inequality in science and technology further disadvantages marginalized people. For example, algorithms increase inequality in US social services for people previously marginalized by low-income (Eubanks 2018). In another example, controversial STEM cell research may incur serious health problems for poor egg donors, women who are already marginalized by their gender (Benjamin 2013). These examples point to the question: How can we enhance socio-technical governance to better serve the marginalized?

Recent scholarship within science and technology studies and science policy studies demonstrates increasing interest in socio-technical governance, to include: constructive technology assessment (Schot and Rip 1997), real-time technology assessment (Guston and Sarewitz 2002), socio-technical integration research (Fisher 2007), and responsible research and innovation (Macnaghten et al. 2014; Stilgoe, Owen, and Macnaghten 2013). The above four models conceptualizing socio-technical governance differ from the status quo practice of science and technology policy because they reject the linear model of innovation (Rafols et al. 2011, 633-634); instead they focus on reflexivity, and public engagement (Fisher, Mahajan and Mitcham 2006; Smith and Stirling 2007). Additionally, three other theoretical frameworks, frugal innovation (Papaioannou 2014), grassroots innovation (Smith et al. 2016), and below the radar innovation (Kaplinsky et al. 2009), share specific concerns around how the uneven balance of power and resources affects the production and inauguration of knowledge and innovation, including the participation of marginalized communities, and economic development progress at multiple scales. Altogether, this highlights a need for scholarly guidance towards more equitable and just science and technology solutions for marginalized communities.

This paper will enhance scholarship on socio-technical governance of science and technology to impact marginalized communities. We begin by uncovering a knowledge gap in theories of sociotechnical governance. Then we continue by reviewing literature on undone science, undone technology, inclusive innovation, and their varying approaches to targeting inequality in science and technology policy to address the issues of marginalized communities. Next, we summarize our new intervention, the "targeting inequality protocol". Afterward, we describe our methodology and introduce two cases, utilizing secondary sources, which we evaluate using the "targeting inequality protocol". Finally, the paper ends with a discussion of the protocol's applications, limitations, and directions for future work.

\section{SOCIO-TECHNICAL GOVERNANCE: UPSTREAM, MIDSTREAM AND DOWNSTREAM}

In order to target inequality in science and technology, a simple metaphor suggests there are two main points to intervene into the socio-technical governance process: upstream and downstream. Both upstream and downstream governance processes typically are facilitated by institutions such as 
government agencies, think tanks, committees of elected officials, industry associations, and consumer associations. Upstream policy-making processes affect science and technology research agenda-setting, including the authorization (or suppression) of specific research trajectories. Governments use laws, regulations, and standards to shape scientific and technological trajectories (Fisher, Mahajan and Mitcham 2006). In the US, the federal government shapes upstream science by maintaining a productive innovation environment; it sets budgets for science funding agencies, sets research goals, and regulates scientific inputs and processes (Neal, Smith and McCormick 2008). One example is President Obama's 2013 BRAIN (Brain Research through Advancing Innovative Neurotechnologies) initiative originating a surge of federal funds that shaped many US scientists' research questions around this new scientific bandwagon (Budtz Pedersen and Hendricks 2014; Fujimura 1988).

Downstream policy-making processes affect users after a science or technology has been developed, diffused and adopted. In downstream processes, governments use laws, regulations and standards to intervene in markets shape the use of science and technology (Fisher, Mahajan and Mitcham 2006). Downstream processes more directly affect individual or group access to existing knowledge or technology (Fisher, Mahajan, and Mitcham 2006). For example, the US government banned 3D printer gun blueprint distribution. The scientific and technical knowledge exists, but the government protects the public by preventing this information's release.

Upstream and downstream processes do not fully epitomize the innovation process; therefore, scholars have added midstream modulation (Fisher, Mahajan and Mitcham 2006). Midstream modulation characterizes how scientists and engineers shape the innovation system. It emphasizes that science does not follow a linear path from basic research to applied research. While the metaphor of a direct movement of science and technology through upstream research ideation followed by downstream diffusion in the market is useful, it does not match the actual socio-technical governance process. In reality R\&D has eddies, turbulence and currents that loop back, intersect, and feed upon themselves to impact the innovation system (Fisher, Mahajan and Mitcham 2006; see Figure 1). Inventors might first develop a product and then go back to understand the science or they may develop the science and technological application at the same time (Stokes 1997). 


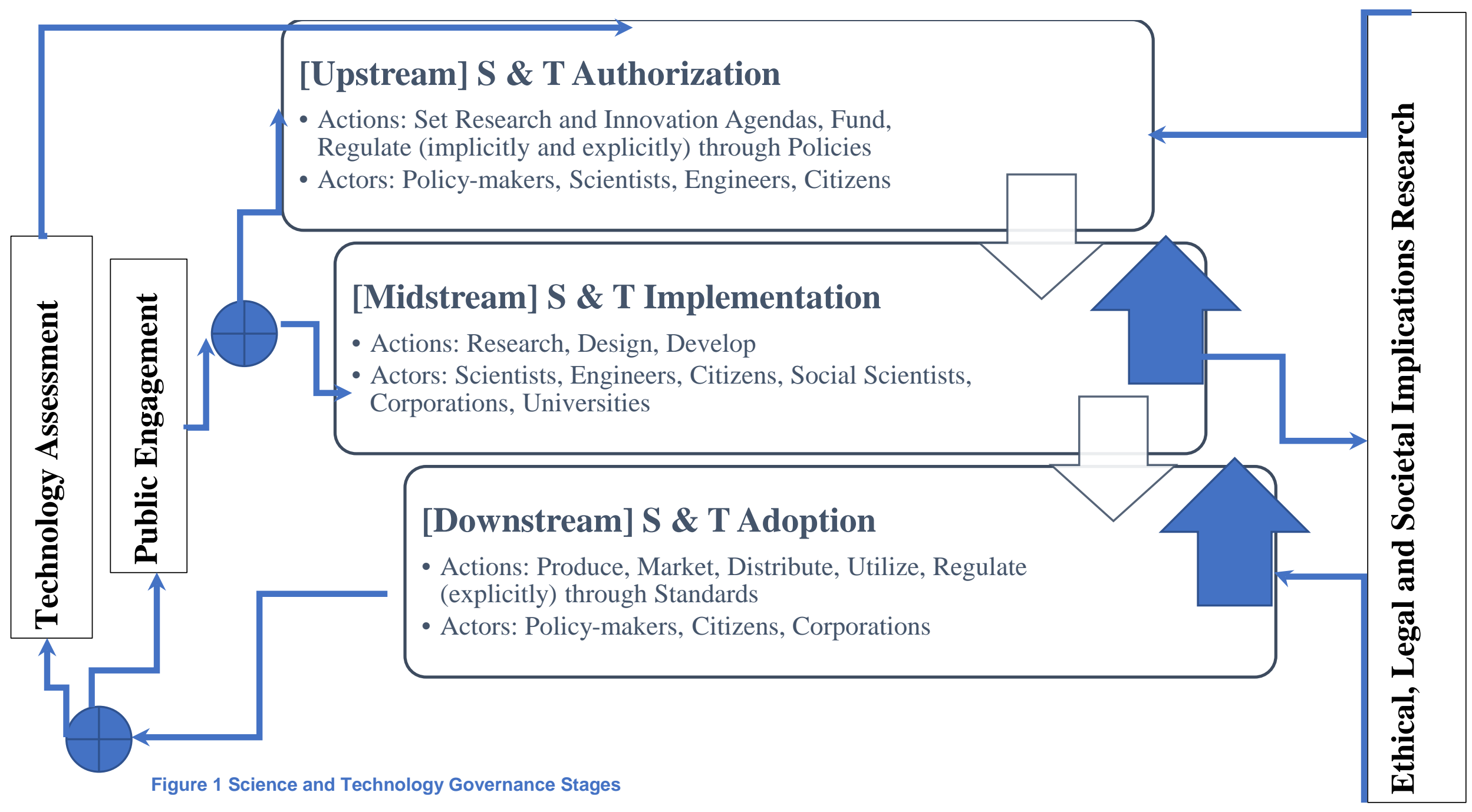

These stages are non-linear, where a linear science and technology policy process (authorization, implementation and adoption) is complicated by nested and iterative interactions by various actors, with different levels of engagement, across and between the three overlapping and fluid stages upstream, midstream and downstream (see Fisher, Mahajan and Mitcham 2006) 
These stages are non-linear, where a linear science and technology policy process (authorization, implementation and adoption) is complicated by nested and iterative interactions by various actors, with different engagement points, across and between the three overlapping and fluid stages upstream, midstream and downstream (see Fisher, Mahajan and Mitcham 2006)"

Midstream policy-making processes affect scientists, engineers, and policy-makers during the research, design, and development stages. In science and engineering laboratories, midstream modulation points towards the potential for social scientists to work together with engineers and natural scientists to intervene in research design and development for social impact (Fisher, Mahajan, and Mitcham 2006; Fisher and Schuurbiers 2013; Gorman et al. 2013; Schuurbiers 2011). The streams metaphor of sociotechnical governance with three overlapping and interrelated phases of upstream, midstream, and downstream directs attention to a more complicated model of innovation. Recent STS and innovation studies concepts about science, ignorance and inequality can further enhance socio-technical governance.

\section{UNCOVERING PROBLEMS IN SOCIO-TECHNICAL GOVERNANCE}

Negative non-knowledge refers to the known unknowns a research system, controlled by powerful elites, deliberately chooses not to pursue due to practical and political interests (Warren 2015). Undone science is systematically-produced negative non-knowledge that would, if available as knowledge, be of interest to marginalized groups and social movements (Hess 2015). Six problems generate inequality in science and technology innovation: infrastructure problem, (2) powerful interests, (3) Eurocentric worldview problem, (4) price-gouging problem, (5) profit incentive problem, and (6) privileged user problem.

The first issue is the infrastructure problem upstream in socio-technical governance. This problem relates to which research questions are funded, ignored, or de-funded and may cause a scientific bandwagon - a popular research problem that attracts public attention, funds, junior researchers and innovators (Woodson and Williams 2018 citing Budtz Pedersen and Hendricks 2014, Fujimura 1988, and Whitley, Gläser, and Laudel 2018). Rarely discussed is that choices about what research problems to pursue (or ignore) typically maintains the status quo of social relations, to the disadvantage of marginalized groups. Therefore, in the infrastructure problem, undone science occurs upstream and involves "a structured absence that emerges from relations of inequality that are reflected in the priorities for what kinds of research should be funded" (Hess 2016, 33).

Another problem that transpires upstream and midstream in socio-technical governance are powerful interests create a chilling effect: they prevent the creation and dissemination of research studies that could negatively reflect upon them. Powerful interests can oppress scientists in their workplaces and suppress research questions (upstream) or research findings (midstream) (Woodson and Williams 2018 citing Greenberg 2003; Delborne 2008; Martin 1981). As a consequence, the powerful interests create undone science as an artificial absence of scientific research pertaining to socio-technical problems in society that would impact marginalized groups. One common example is the power the tobacco industry had to suppress research on how smoking and chewing tobacco causes cancer.

A third problem occurring upstream and midstream in socio-technical governance is a

Eurocentric worldview which assigns greater value to science that uses Western methods and 
epistemology to solve problems interesting to Westerners, thereby biasing the research and development process. This results in higher education gatekeepers (e.g., administrators and grant program officers working upstream, principal investigators and dissertation committee chairs working midstream, etc.) emphasizing Western science above other knowledge systems (Woodson and Williams 2018 citing Englander 2014; Dotson 2014; Hess 1995; Harding 2008; Pereira 2018). Such an emphasis on Western science creates undone science as preventing "new ways of thinking about old scientific problems.... new problems and... new methods or topics of inquiry"(Hess 1995, 185). Scholars and practitioners who are focused on non-Western knowledge systems experience this Eurocentric worldview as "epistemic exclusion"(Cech, et al. 2017; Pereira 2018; Settles, Buchanan and Dotson 2018).

A fourth problem in downstream socio-technical governance is the price-gouging of publicly

funded research. Ignorance can be created when access is restricted to normal science through licenses, patents, or high fees (Woodson and Williams 2018 citing Parthasarathy 2017; Contreras 2013). Since scientific knowledge is often created incrementally, building layer-by-layer upon previous knowledge, this restriction has the potential to create future non-knowledge.

In addition to the above four problems that create non-knowledge (Woodson and Williams 2018), there are two additional problems related to undone technology that create non-users, non-producers and non-artifacts (Williams 2017). Undone science, undone technology, and inclusive innovation should consider how to distinguish and understand by what means inaction blocks knowledge flow or stops innovation production. Prior work on undone science tends to focus on intentional acts by corporate or government parties with interest in particular scientific outcomes. However, sometimes negligence through inaction (whether intended or unintended) can be just as damaging as active stoppages or blockages. Privileging inaction as an analytical lens means the analysis is more focused on what has not been created, and who is not being served, i.e., non-artifacts, non-users and non-markets.

A related problem occurring upstream in socio-technical governance is a narrow motivation - the profit incentive - for technology research, design, and development. Wealth inequality has increased globally; this is connected to the shareholders' strong influence in corporate governance (Clarke, Jarvis, and Gohalamshahi 2018). Large R\&D firms focus on creating blockbuster inventions they can patent and sell in order to make money for shareholders (Williams 2017; Clarke, Jarvis, and Gohalamshahi 2018; Lehoux et al. 2014). These companies give little attention to developing products for marginalized groups (Williams 2017 citing Eglash 2004, Eglash 2016 and Godin 2015). Such singular focus on producing technology for profit restricts who becomes a technology producer creating both non-producers, and a non-market of immaterial non-artifacts. Corporate disinterest in small margins (made by selling low-cost products at high volume) makes the global bottom billion people into a non-market (Williams 2017 citing Prahalad and Hart 2002). This disinterest manifests upstream in socio-technical governance during invention and marketing.

The sixth problem is implicit user identity bias midstream during research, design and development. User identity bias creates privileged users, and their opposite, non-users. The designers, who are typically high-income, white men of European descent, are using the I-methodology (Oudshoorn, Rommes and Stienstra 2004): they are designing for their own needs and they are not actively considering others' needs. Implicit user identity bias occurs when any design team (even one diverse in composition) utilizes blind inclusion where there is naïve (or no) attention to gender, age, class, race, or other components of user identity in design (Pierce 2009). For example, early photography equipment and computer video camera designs demonstrate inattention to lighting for dark skin tones (Roth 2013). The privileged user problem creates technology non-users (Winner 1980; Wyatt 2003) and non-artifacts. This 
privileged user problem tends to occur at the stage of research, design, and development - midstream in the process of science and technology governance.

The six problems described above primarily highlight inequality upstream and midstream in socio-technical governance. Meanwhile, the ladder of inclusive innovation (described below) is a useful heuristic tool to evaluate already developed innovations in the stage of being mass-produced, disseminated and used downstream.

\section{EVALUATING OUTCOMES IN SOCIO-TECHNICAL GOVERNANCE}

The six rung inclusive innovation ladder was developed by scholars as a framework to guide and assess innovations. Higher rungs are progressively harder to reach since more is required for an innovation to be inclusive (Heeks et al. 2013; Heeks, Foster, \& Nugroho 2014).

The first rung on the ladder of inclusive innovation is intent to include; the innovators must propose how their innovations will be inclusive. At this lowest rung, their innovations do not have to prove effective or useful. These innovators demonstrate a shift in mindset from prior innovator. They are at least attempting to develop something to help marginalized communities (Heeks et al. 2013).

The next level, inclusion of consumption, categorizes an inclusive innovation if it is used by a marginalized community. Therefore, it should be useful and accessible. An innovation could be categorized at this level if it was initially consumed. However, the innovation does not have to make a long-term positive impact on a marginalized community. Instead, it may have a negative or negligible impact. Many projects fit onto this rung; a famous failure is the PlayPump ${ }^{\circledR}$ Water System.

The inclusive innovation ladder's third rung is inclusion of impact. At this rung the innovation has demonstrably positive impacts on marginalized groups. The positive benefits could be greater income and ability to consume (absolute impact), or increased capabilities and long-term assets (relative impact). Most innovators want their inventions to at least achieve this rung.

For the ladder's fourth level, an innovation is inclusive if the marginalized group is involved in the innovation process (Heeks et al. 2013, 5). Heeks et al. (2013) break down level 4 into two sets of substeps (see Figure 2). The first set, called the sub-processes of innovation (Heeks et al. 2013), are similar to the stages of research, design, and development in a technology's lifecycle, or the value chain of invention (Williams 2017). This paper directly addresses the second set, which come from Sherry Arnstein's (1969) work on citizen's power and the ladder of public participation.

Level 5, inclusion of structure, focuses on evaluating the institutions that encourage inclusive innovation. At this rung an innovation cannot simply be developed in a company in a wealthy country by residents from a marginalized community. Rather, marginalized groups must participate in governing the institutions that control patenting, markets, education, distribution, employment, etc. and so forth. 


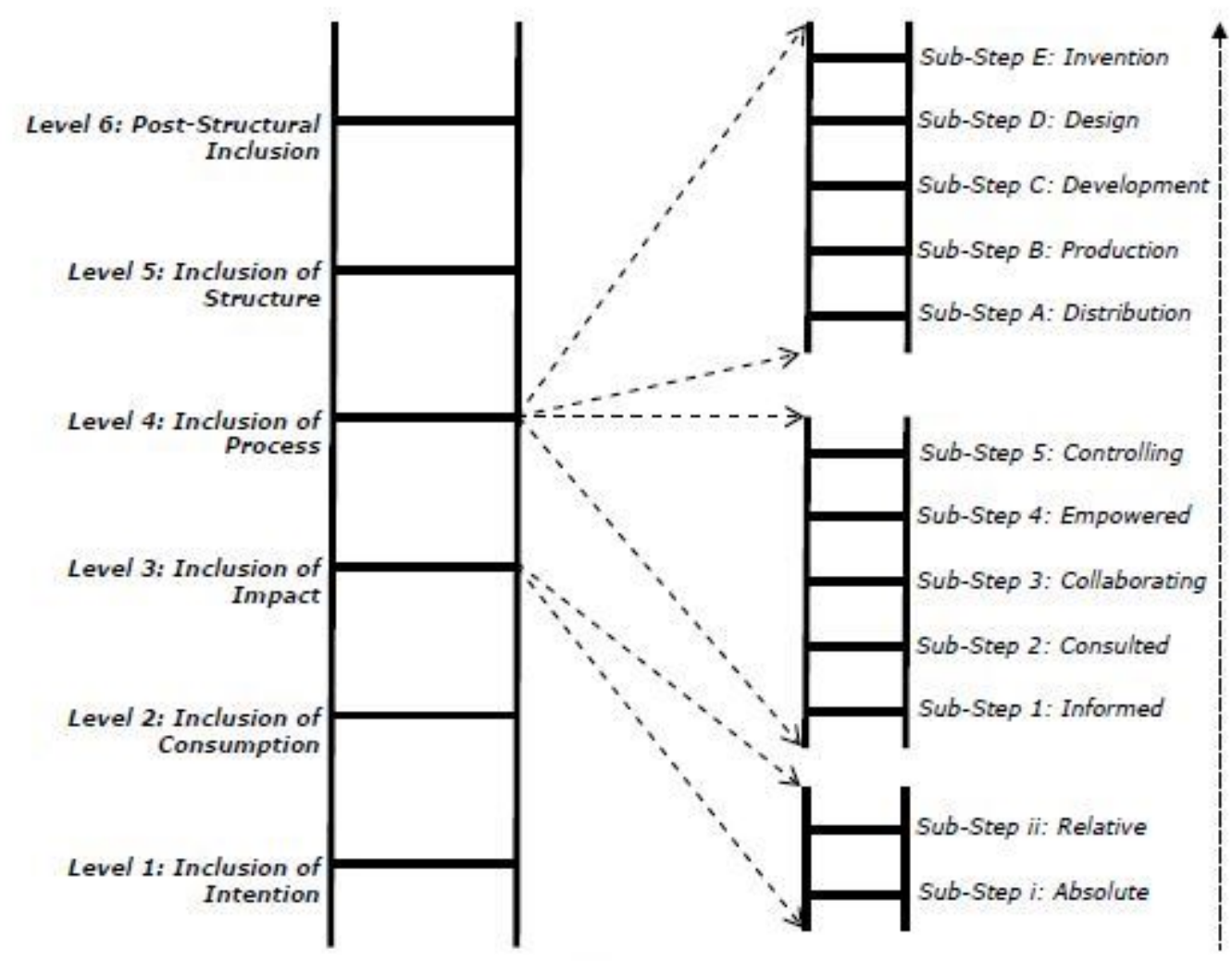

Figure 1 Heeks et al. (2013) Ladder of Inclusive Innovation with Sub-steps for Levels 3 \& 4

The final level, post structural inclusion, is amorphous in definition and very challenging to achieve. At this level, the theoretical frameworks, language and understanding of inequality need to change to make socio-technical governance more inclusive. It would be difficult for a single innovation to achieve this rung, but overtime a series of innovations could reshape how society approaches inclusive innovation. An example of post-structural technologies are household appliances and their ability to transform (or maintain) the roles women, men, children, and servants play in industry and the household (Cockburn and Ormrod 1993; Cowan 1985).

The inclusive innovation ladder does not offer practical guidelines for post-structural inclusion. However, starting with Arnstein's work in the 1960s, there is a substantial literature on public participation in science to inform future efforts. For example, scholars, technology developers, or policymakers interested in using the inclusive innovation ladder can rely on experiential data about the benefits of structured public participation from consensus conferences at Arizona State University and in the Netherlands (Guston 1999; Tomblin et al. 2017). They can build upon this prior work to be selective about the methods of engaging non-experts into discussion in order to move towards post-structural inclusion.

The inclusive innovation literature can benefit from acknowledging that powerful interests allocating limited resources drive undone science; this creates negative non-knowledge that impacts development. The challenge is untangling negative non-knowledge from a resource deficit. Politicians may not pursue a certain project to help a poor community because it conflicts with their interests or alternatively because they cannot afford to pay for necessary infrastructure with other problems taking 
precedence. Sorting out these differing motivations, powerful interests versus low economic resources, is difficult.

In the next section, we use the socio-technical governance streams metaphor to explore the utility of linking together undone science and undone technology with inclusive innovation to create a new protocol. This new protocol is intended for mainstreaming discussions of addressing inequality into sociotechnical governance by, firstly, highlighting common problems of inequality that should be addressed and, secondly, determining if, and how, marginalized peoples (and perspectives) are being maximally incorporated into processes.

\section{THE TARGETING INEQUALITY PROTOCOL}

Although many public administrators and public officials are interested in creating innovation that addresses inequality, there are not many tools available for mainstreaming discussions of inequality into innovation processes, standards, and policies. Two frameworks, Responsible Research and Innovation (Stilgoe, Owen, and Macnaghten 2013) and Responsible Innovation in Health (Lehoux et al. 2018; Pacifico Silva et al. 2018), emphasize inclusivity and diversity are important. However, their potential to intervene to promote inclusive innovation has yet to be realized. Below, we will describe a new protocol focused more narrowly on enhancing the outcomes for marginalized peoples for innovation processes, standards, and policies.

Woodson and Williams (2018) argued that the concepts of undone science, undone technology and inclusive innovation, when utilized together, provide unique insights about inequality in sociotechnical governance that impacts equitable innovation for marginalized groups. Below we further develop and expand this idea into a new protocol by suggesting three strategies for those engaged in science and technology governance upstream, midstream and downstream (see Figure 1). For each strategy, we ask several questions based upon Heeks' inclusive innovation ladder, and, the following concepts from the undone science and undone technology literatures: interested parties, negative nonknowledge, non-producers, chilling effect (scientific suppression), bandwagon effect (scientific bandwagon), blockbuster inventions (profit incentive and non-market), ethnocentric effect (epistemic exclusion), user identity bias (I-methodology and non-users), immaterial non-artifact. When deployed, these strategies build a three part evaluative case study that shines a spotlight on existing inequality in innovation and how it is being addressed (or neglected).

\section{Case Background}

To start with, the case study must define the science or technology under discussion:

1. What is it?

2. Why is it promising or beneficial?

3. Describe its history in more detail. 


\section{Strategy 1 [upstream]: uncover the unexamined inequality before, or while a new innovation is proposed or marketed}

The first strategy is for innovations at the very early proposal stage, or the very late marketing stage (as these stages are very interdependent in most modern corporations).

4. Are blockbuster inventions included in the technology's historical development (Williams 2017)?

5. Which powerful interests care about this non-knowledge (Woodson and Williams 2018)? Alternatively, what non-artifact has been deliberately neglected by technology producers and what was their rationale for creating this non-market (Williams 2017)?

6. Who are the technology users and non-users (Williams 2017)?

7. Who are the science or technology producers and non-producers (Williams 2017)?

8. During upstream socio-technical governance, is a bandwagon effect or ethnocentric effect present (Woodson and Williams 2018)?

\section{Strategy 2 [midstream]: maximize the inclusion of marginalized communities in the innovation process during research, design, and development}

Strategy two focuses on socio-technical governance's midstream phase, where the science or technology is being researched, designed and developed:

9. Are members of the marginalized group involved with any high-value, upstream and midstream, sub-steps in the technology value-chain, that is, invention, design, or development (Heeks et al. 2013, 5; Williams 2017)? Alternatively, how does a marginalized science or technology non-user become a user? Alternatively, how does a marginalized science or technology non-producer become a producer?

10. During midstream socio-technical governance, is an ethnocentric effect or chilling effect present (Woodson and Williams 2018)?

\section{Strategy 3 [downstream]: evaluate equity of tangible outcomes after a new innovation has been produced and distributed,}

The third strategy is about downstream socio-technical governance when science or technology is produced, distributed, and adopted:

11. During downstream socio-technical governance, is a chilling effect suppressing the innovator, knowledge or product (Woodson and Williams 2018)?

12. Did the innovators intend to serve a marginalized community, if so then whom (level 1; Heeks et al. 2013)?

13. Did a marginalized community consume the innovation (level 2; Heeks et al. 2013)?

Alternatively, is a marginalized group restricted from utilizing this knowledge or technology by their inability to pay to access, license or acquire the research results or technology (Woodson and Williams 2018)? 
14. What was the innovation's absolute impact on the marginalized community (level 3; Heeks et al. 2013)?

15. What was the innovation's relative impact on the marginalized community (level 3; Heeks et al. 2013)?

16. Are members of the marginalized group involved with any low-value, downstream, sub-steps of the technology value-chain, that is, production, or distribution (level 4; Heeks et al. 2013, 5)?

17. How were participation opportunities designed to engage marginalized community members, who controlled these opportunities, and do they represent structural inclusion or post-structural inclusion in the ladder of inclusive innovation (Heeks et al. 2013)?

\section{INCLUSIVITY MAINSTREAMING TWO CASES}

To demonstrate the targeting inequality protocol's utility, we use it to evaluate inclusivity mainstreaming: determining if, and how, marginalized peoples (and perspectives) are being maximally incorporated into the model of innovation, while highlighting common problems of inequality that need to be addressed. We collected the empirical data for these two cases in earlier work which we re-examined to generate new insights (Williams 2017; Woodson 2015).

Case 1 is based upon Woodson's study of 3D printing in the US, Kenya and Brazil. The projects in the US and Brazil each included dozens of interviews with experts in the field. Data from the 2013 Digital Inclusion Survey was used to analyze 3D printer adoption, its relationship with community wealth, and its spread throughout public libraries in the US. The US librarians were selected to interview through a stratified random sample. Experts on 3D printing in Brazil were found through an intensive literature review. Because it is on an emerging industry, this case is very useful for demonstrating how the targeting inequality protocol can predict potential problems and bottlenecks upstream and midstream likely impacting the creation of innovation downstream to benefit the marginalized.

Case 2 is based upon Williams' study of community ophthalmology. It started as a larger study where 82 participants were interviewed from 2011-2012 (Williams 2019). Collecting data for this case involved purposive and snowball participant selection, where participants were approached by email first. The 11 interviewees were all South Asian men, in leadership positions. Each interview was conducted one-on-one according to a semi-structured interview questionnaire in their workplace: Aurolab (Madurai, India) or Tilganga-FHIOL (Kathmandu, Nepal). The interviews were audio recorded and transcribed by Accentance, Inc. (Chantilly, Virginia, USA). Data from the interviews was arranged chronologically and by object conflicts (Hess 2005) to arrive at a case study for intraocular lenses. A revisit to Aurolab in 2017 yielded further insights into inclusion of marginalized persons in the innovation process. Since this case is based on new, non-profit innovators in an established industry, it is useful to demonstrate how the targeting inequality protocol highlights how innovators surmounted (or lost) challenges and problems upstream to create more inclusive innovation midstream and downstream.

To demonstrate how the targeting inequality protocol works, the two cases studies are organized as follows: first, we give the new technology's background and, second, we answer questions for the three strategies. 


\section{Case 1: 3D Printing in the US, Kenya and Brazil}

Additive manufacturing (3D printing), is an alternative manufacturing technique using computer models and an ink head to print out a structure by stacking material layer by layer. Over the past five years, 3D printing has received more attention as the next revolutionary technology. Economists predicted the 3D printing market would increase $45 \%$ a year (Canalys 2015), public intellectuals explained how the technology would change the economy (Rifkin 2012), and world leaders predicted it could transform old manufacturing towns into production centers (Obama 2013).

3D printing has at least three advantages over traditional manufacturing. First, it allows designers to create objects which are impossible to create through subtractive practices (Lipson and Kurman 2013). For example, it is possible to 3D print an object with internal moving parts without modifying the external casing. Second, the designs for 3D printing can easily be tweaked to suit the user's needs, offering another advantage (Lipson and Kurman 2013). It is difficult to customize a product in traditional manufacturing because assembly lines are intended to generate duplicates quickly and cheaply. In contrast, 3D printing allows consumers to change the design and print another object. Cheap customization could lead to on-demand products and spur experimentation. A third advantage is 3D printers' potential to reshape the supply chain. In today's global economy, products are shipped around the world to be manufactured and distributed. 3D printers will allow customers to simply download and print the design from their homes. Instead of a long distribution channel requiring shipping containers, ports, roads or stores to supply various products, there is the potential for a much shorter distribution channel: the 3D printers and the raw materials to feed them (sourced locally, or from recycled waste). If individuals are able to use 3D printers to become technology producers, this emerging technology could support projects to generate justice (Eglash 2016).

3D printers were first developed in the 1980s, however, the first companies made them for large corporations. These early 3D printing companies built giant machines used mostly for prototyping expensive industrial parts. Their patent protections meant the technology stayed very expensive and there was little novelty. The early technology developers had tunnel vision about the potential market for 3D printing. By only looking towards corporate sales, they stifled innovation and prevented the technology from spreading to non-industrial and low-income consumers. These patents exemplify creating nonproducers of undone technology (Williams 2017). Patent monopolies prevented early innovation in 3D printing in the global south. As a consequence, the initial introduction of 3D printing to Brazil illustrates getting undone technology done.

The undone science and undone technology scholarly lens can be used upstream to explain how the potential impacts of $3 D$ printing are constrained, how marginalized groups are excluded, and whether this is an intentional process by elites. Although the technology potentially has wide applicability it is unclear what specific problem the global 3D printing industry solves. Additionally, it is unclear if the scientific processes, and material choices are replicable everywhere, or easily sourced (Kleinman 1998). In a parallel example, a critique suggests lab-on-a-chip machines require less skill to operate, but also more expensive company-branded chemicals in comparison to the older, bulkier sequence of Polymerase Chain Reaction machines and spectrometers that fulfill the same purpose (Malkin 2007, 581). There might be a similar critique of 3D printers which offer individual creativity and flexibility, but may require expensive, hard to access materials to keep working. It is possible the cost to circulate these materials and components, which often are coming from outside of Africa, exclude certain non-users from participating. 
Undone science and undone technology also asks about failure to act. Perhaps the global 3D printing industry is not: creating 3D printer designs that serve underserved user groups, or; supporting low income countries' (or people's)involvement in 3D printer production. Once many key 3D printing patents expired in the 2000s, there was a flood of novelty (Schoffer 2016). New companies started making cheap 3D printers based on expired patents, and the tinkerers developed open source printers, like the RepRap. At first much innovation was in wealthy countries, but innovators in lower income countries quickly got involved. The small consumer printers developed in the USA were still out of reach for most consumers in low/middle income countries due to the cost and the challenge in getting replacement parts, so innovators in those countries developed their own 3D printers. In Brazil, several 3D printer firms, like Metamaquina (Woodson, Alcantara \& Silva 2019), were started and, in Kenya, young innovators built 3D printers out of electronic waste (“AB3D Printing” 2016). These innovations would not have occurred if 3D printing had been blocked by price-gouging normal science or if the early patents had been evergreened. Currently, individuals and corporations are participating in the 3D printing industry. However, individual users and producers are predominantly young (23-34 years), STEM educated men who trained in wealthy countries (Thimmesch 2015).

The 3D printing industry does not appear to be deliberately blocking or restricting individual access to 3D printing equipment. Instead, Woodson (2015) finds many libraries purchased 3D printers so the public would have access to them. Public libraries are designed to be open access points to knowledge where people, regardless of status, can access and learn information. More recently, citizens in public libraries can access key technologies like computers, digital cameras and tablets (Jue et al. 1999). If a public library is successful in its mission, then the access to knowledge will be democratized. Therefore, this was a laudable intent to keep access to the new knowledge and equipment unrestricted.

If the library-based 3D printers increase diversity (e.g., class, race, gender, etc.) among users, that would signal increased inclusivity in the innovation process, the change of non-users into users and, possibly, the change of non-producers into producers.

Undone science and undone technology asks whether the global 3D printing industry is pricing out smaller competitors in less economically developed countries. This would be the expected way for large companies to block technology production and create non-producers. Instead, new companies in Kenya are circumventing international patent law. These Kenyan companies use appropriation (Williams and Woodson 2012) by cannibalizing electronic waste from old computers to create the new 3D printers. Thus far, neither international trade regulations, nor national commerce, nor other national regulations are preventing this appropriation work. The result is a new addition to the 3D printing industry, one which also contributes to the recycling and re-use of electronic waste. From the critical perspective of undone science, it is encouraging the Kenyan companies have not been prevented from building a 3D printing business around electronic waste. The lack of regulation enforcement provides a necessary flexibility in the local innovation system at early stages of research, design, and development.

The undone science theoretical framework suggests the 3D printing industrial culture could be investigated epistemologically. Scholars might consider what sorts of flexible, individually tailored, small, and non-durable products are enabled through 3D printing versus traditional manufacturing. Furthermore, policy-makers could think ahead to the future consequences of 3D printed products over traditionally manufactured products; this gets at the underlying values enabled by 3D printing in comparison to traditional manufacturing. Systematically considering the underlying knowledge system and associated values of 3D printing might result in further insights and suggest their policy implications for upstream agenda-setting. 
Compared to other technologies, there is less upstream governance of 3D printing because there is such an open source mentality in the 3D printing culture. High level government officials have discussed 3D printing's potential to transform economies, so the technology is expected to receive substantial support upstream. This support will likely cause bandwagon effects where researchers and scholars will chase 3D printing funding.

At midstream of socio-technical governance, there is a greater emphasis on including marginalized people in high-value innovation processes such as research, design and development. Woodson (2015) claims 3D printing cannot truly address inequality and poverty without governmental support through policy initiatives; otherwise engineers, corporations and other elite groups retain their privilege. However, poor and uneducated groups do not fully engage with 3D printing (Woodson 2015). Typically, there is much excitement about the technology when it is first explained. However, as community members begin to use the technology, they quickly discover the challenges with designing useful products using the cheap and accessible 3D printers. A few problems include: it is challenging to create a new 3D design without proper training; the printed artifacts may not be sturdy; and it takes a long time to print the actual part. As a result, many novice users ultimately remain non-users.

Despite the challenges, some marginalized groups are involved in the invention, design and development of 3D printers. In both Kenya and Brazil, local innovators are developing new types of 3D printers. In Kenya, AB3D built printers from electronic waste; in Brazil there are many makerspaces and hackerspaces developing 3D printing technology. The challenge is moving the technology from powerful groups within these mid/low income countries to marginalized communities in these countries.

This challenge is complicated by the ethnocentric effects implicated in 3D printing. Even though innovators in Brazil are developing the new technology, many were trained in the USA or Europe. Consequently the epistemological patterns travel with those innovators from their training sites in the West to the 3D printing culture in Brazil. On the one hand, Brazilian innovators are peripheralized in the global 3D printing industry, compared to the centered West. Thus they act to counter epistemic exclusion of non-Western perspectives in the 3D printing research, design, and development. On the other hand, these Brazilian innovators are the high-tech elites of Brazil involved in local entrepreneurship around 3D printing in comparison to low-income or other social identity groups in Brazil who do not have such opportunities.

Downstream socio-technical governance should include reflection on levels of inclusivity at various stages of production and diffusion (or distribution). Brazilian import regulations epitomize the downstream chilling effect. Interestingly, Brazil often uses these tariffs to encourage local innovation (Aguirre-bastos and Gupta 2009). However, many local inventors said the import tariffs made it very challenging for them to get parts to make 3D printers. The import substitution policy is not as strong as in the 1970s and 1980s, yet Brazil still has high tariffs compared to other countries (Goedhuys and Veugelers 2009). Though Brazil wants to encourage local innovation by having tariffs on imported parts, it chills the local 3D printing research.

Woodson (2015) uses Heeks' inclusive innovation ladder to identify opportunities for 3D printers to decrease poverty and inequality in the global south. In particular, his analysis focuses on challenges African countries will face with using 3D printers to help marginalized communities. Woodson (2015) points out the level 1 criteria of intent to address inequality is not equivalent to solving the problem of inequality. He describes an example where the intent to serve marginalized communities by placing 3D printers in publicly accessible libraries did not actually meet its goal. Additionally, Woodson (2015) suggests the level 2 criteria of consumption cannot be used to characterize whether an innovation 
addresses issues of poverty and inequality, without additionally considering the imbalanced consumption proportions between the marginalized and the elite. Subsequently, for the level 3 criteria of impact, Woodson (2015) recommends that impact must be carefully defined to account for technology's introduction to marginalized individuals including both long-term measurement, and a community-based understanding of intended and unintended consequences.

In one sense since the 3D printing innovations are taking place in Brazil, a marginalized community (that is, non-Western) is involved in the low-value, downstream, activities of producing and distributing the technology. However, within Brazil, very few people from marginalized communities are involved in producing and distributing 3D printers. At most, marginalized groups are absorbing and using the technology. 3D printer's complicated nature means inclusivity (Heeks level 4) occurs (and is prevented) on many different scales.

For the level 5 criteria of structure, Woodson (2015) contends 3D printing is an opportunity for governments, civil society actors, and corporations to discuss the innovation system's structure at different scales. He argues the current 3D printing innovation system (based on patents, higher education, and taxes) is not inclusive. This negates the need for discussing post-structural inclusion (level 6 of Heeks et al. 2013).

Next, the second case describes two non-profit technology companies who have begun to reach high levels of inclusivity in their efforts to eradicate blindness due to preventable causes.

\section{Case 2: Intraocular lenses in India and Nepal}

Intraocular lenses (IOLs) are similar to the natural lens which focuses light onto the back of the eye. When cataract disease obscures the natural lens, an ophthalmologist will surgically remove it, and replace it with a plastic intraocular lens. The intraocular lens was first invented by a British ophthalmologist in the 1940s; starting in the 1980s, it was a regular practice for ophthalmologists in the US and UK to insert IOLs into patients blind due to cataract disease (Williams 2019 citing Metcalfe, James and Mina 2005).

Three features made IOLs more promising in comparison to the previous technology standard, aphakic "cokebottle" glasses (Williams 2019). First, the intraocular lens made it viable for ophthalmologists to operate on one eye at a time. In contrast, aphakic glasses worked best as a postsurgical visual aid when utilized for both eyes. Therefore, patients had to wait for vision in both eyes to deteriorate due to cataract disease before even one eye could be operated upon. Second, the intraocular lens provided better post-surgical vision than aphakic glasses, that is, the patients had better peripheral vision. The third reason why intraocular lenses were considered more beneficial than aphakic glasses is because they were implanted biomedical prosthetics. As such, an IOL could not accidentally be lost or broken. Aphakic glasses, on the other hand, could break, leaving the patient functionally blind again (Williams 2019).

Establishing Aurolab and Tilganga-FHIOL went against an ethnocentric, Western worldview that thought companies in developing countries could not create reliable, bio-compatible ophthalmic devices (Williams 2019). Avoidable blindness affects 39 million people around the world. Fifty percent of avoidable blindness is caused by cataract disease. Yet, IOLs produced by multinational companies such as Alcon (Novartis) were priced above the average Indian monthly wage (Williams 2019).

Aurolab started in 1992 in the southern state of Tamil Nadu and quickly began to provide reasonably priced IOLs to Indian patients undergoing cataract surgery (Williams 2019). It was among the 
first ophthalmic consumables company in India (Williams 2017). Tilganga-FHIOL began in 1993 and produced its first IOLs in 1994 (Williams 2019).

At the upstream phase of socio-technical governance, the concepts of undone science and undone technology help explain how Aurolab and Tilganga-FHIOL are examples of civil society organizations serving a new market, with new users while becoming technology producers. At first, as multinational companies chased the next big blockbuster invention in IOLs, they were willing to donate their unsold, less popular inventory to ophthalmologists in the global south. Eventually, as the market for IOLs became saturated, the multinational companies stopped donating the less popular lenses so they could sell them for the smaller margins (Williams 2019). There was no source available for low-cost IOLs for lowincome blind people; low-cost IOLs were non-artifacts. They were also deemed immaterial (or irrelevant) as existing multinational companies declined to develop inexpensive IOLs for low-income patients.

In the late 1980s and early 1990s, the cheapest IOLs were still too expensive for the average worker in the global south. IOLs' high cost, combined with the opportunity and travel costs of free cataract surgery, meant surgically corrected sight was not feasible for many low-income Indian and Nepalese blind patients (Williams 2019). In the US, old inexpensive IOLs cost \$200 USD; meanwhile, new foldable, accommodating and other IOL designs costs hundreds more. Aurolab and Tilganga-FHIOL used turnkey technology transfer to develop their own laboratories in India and Nepal, followed by reverse engineering to create inexpensive IOLs (Williams 2019). The target price was \$10 USD for Aurolab IOLs and \$4 USD for Tilganga-FHIOL IOLs.

Before they created their own laboratories, they encountered both a chilling effect and an ethnocentric effect. Western experts claimed that pursuing IOL manufacturing was reaching beyond the capabilities of developing countries (ethnocentric effect). These Western experts opined individually and also collectively through the official World Health Organization (WHO) 1986 report on cataract management (Williams 2019). Indian ophthalmologists were likewise concerned that creating a new, local, manufacturing laboratory would result in low quality IOLs in the local market (ethnocentric effect; Williams 2019). The World Bank agreed with the WHO. Meanwhile, the Indian government agreed with the World Bank, a prominent funder of India's National Program for Prevention of Visual Impairment and Control of Blindness (Williams 2019).

In addition to experiencing the ethnocentric effect from the WHO, the founders of TilgangaFHIOL in Nepal experienced a chilling effect. Local Nepalese ophthalmologists tried to discredit Tilganga's primary founder as he was seeking funds and approval from His Majesty's Government to authorize a new intraocular lens laboratory. Ultimately, Tilganga relied upon local Nepalese businessmen, a New Zealand ophthalmologist, an Australian NGO, and the Australian government for the funds to create both the eye institute and the IOL manufacturing laboratory (Williams 2019).

Early funding helped Aurolab develop a regional market for their IOLs. Although the Indian government did not directly support Aurolab, their blindness control program provided funds for training and re-training ophthalmologists in advanced surgery techniques including IOL implantation. Aurolab profited from some of these educated ophthalmologists electing to purchase Aurolab lenses instead of multinational company branded IOLs for their Indian patients. Finally, no bandwagon effect was present. At the midstream phase of socio-technical governance, experts (e.g., engineers and medical physicians, etc.) work on high value innovation processes such as invention, research, design and development. Heeks et al. (2013) was interested in how these innovation processes might be made more inclusive. One mechanism is to broaden the diversity of experts by ensuring people from marginalized communities are involved. The case of IOLs in India and Nepal demonstrates this at two scales: On the 
international stage there were many non-western experts and users involved in the projects. On the national stage, this case demonstrates greater inclusivity as many of these non-western experts were born in rural villages in South Asia, and were therefore highly focused on providing eye health care to these areas because their desire to give back to their own communities. As in many countries around the world, folks from rural areas tend to be overlooked by urbanites from high-tech city centers. On the local stage this case does not demonstrate grater inclusivity: the non-Western experts were, with a few exceptions, college-educated, upper and middle class, men of higher caste.

Aurolab and Tilganga-FHIOL were both non-producers that became endogenous technology producers in the respective countries of India and Nepal. Tilganga-FHIOL focused on producing low-cost IOLs, and creating access to low cost ultrasound equipment for cataract surgery (Williams 2019). Aurolab has additionally moved up the global value chain of invention to conduct research and design (midstream processes). India has well-established biotechnology industry, yet it mostly manufactures generic drugs for sale in the global market (Williams 2017). Aurolab went from non-producer to producer by: being among the first ophthalmic consumables manufacturers in India; relying, in part, on Western companies to do the expensive, high value, research and development which they reverse engineer to create their own branded products to meet the needs of local, marginalized groups; manufacturing original product designs for sale under Western brands; and researching and developing novel orphan drugs to meet the needs of local, marginalized groups (Williams 2017).

Before Aurolab was created, there was little infrastructure present to create the tools, instruments, drugs, biomedical prosthetics, and other ophthalmic consumables at low cost for poor blind patients in less economically developed countries. Aurolab is large by volume, but not by profits, when compared to other multinational ophthalmic companies such as Alcon. After starting with small batches, Aurolab had to quickly grow to become a large technology producer to best combat the indifference of existing governments and large technology producers in the global biomedical industry towards the large nonmarket of non-users, that is, poor, blind consumers in India and around the world. Later Aurolab branched out to get other undone technology done. This includes a novel glaucoma drug that does not require refrigeration, and a novel intraocular lens design that prevents post-surgical complications (Williams 2017).

Evaluating Aurolab and Tilganga-FHIOL downstream in socio-technical governance reveals they are developing and disseminating inclusive innovations. First, Aurolab and Tilganga-FHIOL demonstrate Level 1 on the ladder of inclusive innovation: intent to serve marginalized communities. Since it is a subsidiary of a larger non-profit charitable trust called Aravind Eye Care System, Aurolab has always minimized its profits in order to keep product prices low and maximize how many blind patients it serves (Aurolab n.d.; Williams 2017). Tilganga-FHIOL is likewise organized as a non-profit with an important mission to provide low-cost consumables and instruments.

Aurolab and Tilganga-FHIOL use a combination of technology transfer, design and development to deliberately maintain low profit margins and focus on making medical products more accessible to the blind poor around the world (Williams 2013; 2017; 2019). Both manufacturers have established reputations for providing inexpensive and high-quality ophthalmic consumables and instruments while partnering with other (primarily non-profit) organizations that supply their products to marginalized communities around the world.

Second, the technology developed by Aurolab and Tilganga-FHIOL has clearly been utilized by marginalized communities; this addresses Level 2 on the ladder of inclusive innovation, consumption (Heeks et al. 2013). Aurolab and Tilganga-FHIOL serve technology non-users in a marginalized 
community of rural and urban blind poor in less economically developed countries around the world. In India in 1989, this non-market included 12 million blind people; of those, 80\% were blind from cataract disease (Williams 2019). Indeed, the case of Aurolab manufacturing intraocular lenses in India has been previously conceptualized as a "bottom of the pyramid innovation" (Prahalad and Hart 2002).

In 1999, Aurolab was the first Indian IOL manufacturer to get the CE mark (certifying their product for consumption in the European Union); they sell to 130 countries around the world, primarily to other LEDCs (Aurolab n.d.; Williams 2017, 2019). Aurolab's nylon and silk sutures, which received US FDA approval in 2003, are sold in the US under another company's brand name. Tilganga-FHIOL lenses are sold in other LEDCs and also Australia. In 2012, Tilganga-FHIOL lenses were the only Nepalese product with the CE mark; they have had this certification since 1998. Tilganga-FHIOL lenses also have the Australian Therapeutic Goods Administration (TGA) certificate. Tilganga-FHIOL was the first Nepalese company to attempt to meet ISO 9001 quality assurance standards. Interesting from a cost engineering standpoint: Tilganga-FHIOL lenses are individually checked (a high labor cost), not batch checked (a low labor cost), where individual checks arguably yield higher quality lenses.

Thirdly, there is positive impact both absolute and relative (see Heeks et al. 2013). While Aurolab and Tilganga-FHIOL are not the only low cost ophthalmic consumable and equipment manufacturers in the world, they, along with FHIOL-Eritrea are among the only three non-profit ophthalmic consumable and equipment manufacturers globally. The absolute impact occurs through increased consumption of IOLs, and thus increased cataract surgeries worldwide. The managing-director of Aurolab, Sriram D. Ravilla explains, "We sell 7 to 8 percent [of the IOL global sales volume] so we should make 80 to 90 million U.S. dollars, but our IOL division made less than 10 million U.S. dollars. We priced it that way" (Aurolab n.d.; Williams 2019, 169). In addition to IOLs, Aurolab has expanded their manufacturing to create other inexpensive tools, equipment, consumables, and drugs for use by ophthalmologists and their low-income patients. Aurolab's growth is supported from purchases made by both non-profit and forprofit eye surgical clinics around the world for their poor blind patients. However, both Aurolab's and Tilganga-FHIOL's primary customers are non-profit organizations fighting avoidable blindness among the poor around the world such as: Nepal Netra Jyoti Sangh (Nepal), Christian Blind Mission (Germany) and SEVA Foundation (USA).

Aurolab and Tilganga-FHIOL are part of implementing the joint World Health OrganizationInternational Agency for the Prevention of Blindness (IAPB) Vision 2020 program. Many non-profit organizations, the Fred Hollows Foundation, IAPB, Sightsavers International, Light for the World, CBM International, and Operational Eyesight Universal, commissioned a cost-benefit analysis by PriceWater Cooper. Their report says, "In developing countries, we estimate the total benefits [of Vision 2020] to be at least \$517.1 billion (2009 USD) over the ten years from 2011 to 2020, significantly outweighing the additional investment required (\$128.2 billion 2009 USD), a benefit cost ratio of some 4.0 times the cost"(Fred Hollows Foundation 2013, 4). This additional absolute impact increases funds spent on eradicating and preventing blindness.

The relative impact occurs through decreased projections for future blindness rates worldwide, and increased projections for better livelihoods (with fewer years lost due to ill-health, disability or early death) worldwide. "Benefits that were not able to be quantified due to a lack of supporting data that have been analysed [sic] qualitatively include increased primary education, reduced extreme poverty, increased independence, self-esteem and improved social networks and increased gender equality"(Fred Hollows Foundation 2013, 9). 
For Level 4, inclusion in the innovation process, Aurolab's production facility employs marginalized Indians such as: low income women, persons of non-Hindu faith, and individuals with disabilities (deaf and mute women). The production jobs give Aurolab employees the opportunity to make a good income while working to benefit society. Aurolab finds that university graduates apply for production jobs, however, Aurolab primarily hires women with high school diplomas. Unfortunately, with a few exceptions, it is rare for a person on the production line to move up through the company's ranks. In contrast, Tilganga-FHIOL, which employs educated urbanite men and women from Kathmandu on their production line, might consider how to seek out, train, and employ more marginalized people.

Finally, there is some limited evidence of level 5, structural inclusion, and level 6, post-structural inclusion. At level 5, Aurolab and Tilganga-FHIOL are changing the market for innovations by revealing both the economic and social value of developing medical products for marginalized communities. Through their efforts, there are new business models to develop technologies for marginalized populations. At level 6, Aurolab and Tilganga-FHIOL are changing the perception of innovation's geopolitical location. They demonstrate that innovation does not only take place in wealthy countries and it is possible for innovations to move from low income countries to high income countries (Williams 2013; 2019).

\section{Discussion}

Evaluating 3D printing with the targeting inequality protocol demonstrates potential problems upstream and midstream. Upstream socio-technical bottlenecks identified by local entrepreneurs in Brazil and Kenya include how materials and patents impact 3D printer designs, and 3D printing's long-term economic viability. Inclusivity bottlenecks included determining the method, beyond public libraries, to transform marginalized communities within countries in the global south from non-users into users of 3D printers. Becoming a 3D printing user requires specific levels of education and skill despite 3D printing's promise of flexibility and ease-of-use. However, many marginalized non-users in the global south are disadvantaged by less education and little experience with technology in comparison to existing Western users. The original 3D printing creators ignored this user identity bias. Therefore, new methods (likely borrowed from community engagement participatory methods) should be implemented downstream to transform marginalized non-users into 3D printing users.

Evaluating IOLs with the targeting inequality protocol demonstrates how innovators surmounted (or lost) challenges and problems upstream to create more inclusive innovation midstream and downstream. Many (Western and South Asian) medical scientists' expert opinions were based in an ethnocentric worldview which, unfortunately, biased them against the capabilities of their non-Western peers to develop risky high-technology in South Asia. They set up roadblocks against these novice innovators for arbitrary reasons. However, these novice innovators transformed themselves from IOL users to producers while maintaining an emphasis on serving marginalized communities. They were thoughtful about integrating diverse perspectives and people throughout their design, development, and production processes. These two non-profit technology companies illustrate how to create inclusive careers and inclusive products for marginalized communities.

When writing the two cases, we found utilizing the protocol helped to draw out insights we had not previously considered. For example, protocol strategy 1 suggested provocations for the emerging 3D Printing industry in the US, Kenya and Brazil that might be thoughtfully considered during upstream socio-technical governance, but, as yet, do not have empirical answers. Protocol strategy 1 predicted the 
potential blocks that powerful interests might construct in 3D printing. As the old Latin proverb suggests "forewarned is forearmed" for visionaries interested in creating more inclusive innovation. Therefore, it seems the targeting inequality protocol, with its three strategies, is useful for building an evaluative case that can both forewarn of potential problems, and, demonstrate potential actions to solve historical problems in creating inclusive innovation. This makes the targeting inequality protocol a useful addition to socio-technical governance upstream, midstream and downstream in the innovation process.

A major limitation in this research is our failure to interrogate the starting assumption of sociotechnical governance: science and technology's positive role for enhancing society, especially in marginalized communities within the global south. The relationship between science, technology and international development is complicated, especially because it is intertwined with postcolonial relationships between states with uneven access to resources (Cherlet 2014; Shrum 2015; Bauchspies 2014). Typically, the "adoption of a new technology selectively creates new absences and presences that are shaped by existing social relations" (Bauchspies 2014, 65; Winner 1980). Future work might include challenging this starting assumption and rigorously defining circumstances where addressing inequality does not require science and technology innovation. Likewise, future policies for development may require a more thoughtful look at what innovations are already present locally, and from there extrapolating how science as a social institution can aid in appropriating science and technology to best fit local needs and visions for the future (Bauchspies 2014; Williams and Woodson 2012).

\section{CONCLUSION}

In summary, our goal was to make a tool to highlight inequality in science and technology innovation processes. To that end, we developed a new protocol to mainstream discussions of inequality and inclusivity in socio-technical governance. We utilized the socio-technical governance stream metaphor with its interesting actions, points of feedback, and reflection points upstream, midstream, and downstream (Fisher, Mahajan and Mitcham 2006). Next, we described six problems that generate inequality primarily upstream and midstream during socio-technical governance of innovation: the infrastructure problem (scientific bandwagons upstream creates non-knowledge), the powerful interests problem (chilling effect midstream and downstream creates non-knowledge), and the Eurocentric worldview problem (ethnocentric effect upstream and midstream creates non-knowledge), price-gouging problem (blocked access to normal science downstream), profit incentive problem (emphasis on the next blockbuster invention creates non-artifacts upstream), the privileged user problem (user identity bias creates non-users midstream). Five of these six problems are typically co-constructed with ignorance and negative non-knowledge or non-artifacts. The inclusive innovation ladder is a useful heuristic to evaluate the equity of outcomes while science and technology is being researched, designed and developed (midstream) and after science and technology has been produced and distributed (downstream). The "targeting inequality" protocol uncovers six problems that generate inequality (forward looking), and also evaluates inclusivity with a heuristic tool (backwards looking). Altogether, this unique protocol can uncover problems, evaluate outcomes, and suggest actions with the end result of inclusivity mainstreaming socio-technical governance. 


\section{REFERENCES}

Arnstein, Sherry R. A Ladder of Citizen Participation. Journal of the American Institute of Planners 35, no. 4 (July 1, 1969): 216-24. https://doi.org/10.1080/01944366908977225.

Aurolab. n.d. Aurolab Corporate Brochure. Aurolab.

http://www.aurolab.com/images/AurolabCorporateBrochure.pdf.

Bauchspies, Wenda K. 2014. Presence from Absence: Looking within the Triad of Science, Technology and Development. Social Epistemology 28 (1):56-69.

https://doi.org/10.1080/02691728.2013.862877.

Benjamin, Ruha. 2013. People’s Science Bodies and Rights on the Stem Cell Frontier. Stanford, California: Stanford University Press. http://site.ebrary.com/id/10731954.

Budtz Pedersen, David, and Vincent F. Hendricks. 2014. Science Bubbles. Philosophy \& Technology 27 (4): 503-18. https://doi.org/10.1007/s13347-013-0142-7.

Cech, Erin A., Anneke Metz, Jessi L. Smith, and Karen deVries. 2017. Epistemological Dominance and Social Inequality: Experiences of Native American Science, Engineering, and Health Students. Science, Technology, \& Human Values 42 (5): 743-74. https://doi.org/10.1177/0162243916687037.

Cherlet, Jan. 2014. Epistemic and Technological Determinism in Development Aid. Science, Technology, \& Human Values 39 (6):773-94. https://doi.org/10.1177/0162243913516806.

Clarke, Thomas, Walter Jarvis, and Soheyla Gholamshahi. 2018. The Impact of Corporate Governance on Compounding Inequality: Maximising Shareholder Value and Inflating Executive Pay. Critical Perspectives on Accounting, July. https://doi.org/10.1016/j.cpa.2018.06.002.

Cockburn, Cynthia, and Susan Ormrod. 1993. Gender and Technology in the Making. London; Thousand Oaks, Calif.: Sage.

Contreras, Jorge. 2013. Confronting the Crisis in Scientific Publishing: Latency, Licensing, and Access. Santa Clara Law Review 53 (2): 491.

Cowan, Ruth Schwartz. 1985. More Work For Mother: The Ironies Of Household Technology From The Open Hearth To The Microwave. Basic Books.

Delborne, Jason A. 2008. Transgenes and Transgressions: Scientific Dissent as Heterogeneous Practice. Social Studies of Science 38 (4):509-541.

Dotson, Kristie. 2014. Conceptualizing Epistemic Oppression. Social Epistemology 28 (2): 115-38.

Eglash, Ron. 2004. Appropriating Technology: An Introduction. In Appropriating Technology: Vernacular Science and Social Power, ed. Ron Eglash, Jennifer L. Croissant, Giovanna Di Chiro, and Rayvon Fouché, vii-xxi. University of Minnesota Press.

- 2016. Of Marx and Makers: an Historical Perspective on Generative Justice. Teknokultura. Journal of Digital Culture and Social Movements 13 (1):245-69. https://doi.org/10.5209/rev_TK.2016.v13.n1.52096. 
Englander, Karen. 2014. The Rise of English as the Language of Science. In Writing and Publishing Science Research Papers in English, by Karen Englander, 3-4. Dordrecht: Springer Netherlands.

Eubanks, Virginia. 2018. Automating Inequality: How High-Tech Tools Profile, Police, and Punish the Poor. St. Martin’s Press.

Fisher, Erik. 2007. Ethnographic Invention: Probing the Capacity of Laboratory Decisions. NanoEthics 1 (2): 155-65.

Fisher, E., Mahajan, R.L., Mitcham, C., 2006. Midstream Modulation of Technology: Governance From Within. Bull. Sci. Technol. Soc. 26, 485-496.

Fisher, Erik, and Daan Schuurbiers. 2013. Socio-Technical Integration Research: Collaborative Inquiry at the Midstream of Research and Development. In Early Engagement and New Technologies:

Opening up the Laboratory, ed. Neelke Doorn, Daan Schuurbiers, Ibo van de Poel, and Michael E. Gorman, 97-110. Philosophy of Engineering and Technology. Dordrecht: Springer Netherlands. https://doi.org/10.1007/978-94-007-7844-3_5.

The Fred Hollows Foundation. 2013. Investing In Vision: Comparing the Costs and Benefits of Eliminating Avoidable Blindness and Visual Impairment. Australia: Price Water Coopers.

Frickel, Scott, Sahra Gibbon, Jeff Howard, Joanna Kempner, Gwen Ottinger, and David J. Hess. 2010. Undone Science: Charting Social Movement and Civil Society Challenges to Research Agenda Setting. Science, Technology, \& Human Values 35 (4): 444-73.

Fujimura, Joan H. 1988. The Molecular Biological Bandwagon in Cancer Research: Where Social Worlds Meet. Social Problems 35 (3): 261-283.

Godin, Benoît. 2016. Technological Innovation: On the Origins and Development of an Inclusive Concept. Technology and Culture 57 (3):527-56.

Gorman, Michael E., Antonio Calleja-López, Shannon N. Conley, and Farzad Mahootian. 2013. Integrating Ethicists and Social Scientists into Cutting Edge Research and Technological Development. In Early Engagement and New Technologies: Opening up the Laboratory, ed. Neelke Doorn, Daan Schuurbiers, Ibo van de Poel, and Michael E. Gorman, 157-73. Philosophy of Engineering and Technology 16. Springer Netherlands. https://doi.org/10.1007/978-94-0077844-3_8.

Greenberg, Daniel S. 2003. Conference Deplores Corporate Influence on Academic Science. Speakers Argue That Corporate Funds Should Be Separated from Science to Prevent Undue Influence. Lancet (London, England) 362 (9380): 302-3.

Guston, David H., and Daniel Sarewitz. 2002. Real-Time Technology Assessment. Technology in Society, American Perspectives on Science and Technology Policy, 24 (1): 93-109. https://doi.org/10.1016/S0160-791X(01)00047-1.

Guston, David H. 1999. Evaluating the First US Consensus Conference: The Impact of the Citizens' Panel on Telecommunications and the Future of Democracy. Science Technology and Human Values 24 (4):451-82. 
Heeks, Richard, Mirta Amalia, Robert Kintu, and Nishant Shah. 2013. Inclusive Innovation: Definition, Conceptualisation and Future Research Priorities. 53. IDPM Development Informatics Working Papers. Manchester, UK: Centre for Development Informatics, The University of Manchester.

Heeks, R., Foster, C., \& Nugroho, Y. 2014. New models of inclusive innovation for development. Innovation and Development, 0/February 2015: 1-11. DOI: 10.1080/2157930X.2014.928982

Hess, David J., Sulfikar Amir, Scott Frickel, Daniel Lee Kleinman, Kelly Moore, and Logan D. A. Williams. 2016. 11. Structural Inequality and the Politics of Science and Technology. In The Handbook of Science and Technology Studies, ed. Ulrike Felt, Rayvon Fouché, Clark A. Miller, and Laurel Smith-Doerr, 4th ed., 319-47. Cambridge, Massachusetts: The MIT Press.

Hess, David J. 2016. Undone Science: Social Movements, Mobilized Publics, and Industrial Transitions. Cambridge, Massachusetts: MIT Press.

Hess, David J. 2015. Undone Science and Social Movements: A Review and Typology. In Routledge International Handbook of Ignorance Studies, ed. Matthias Gross and Linsey McGoey, 141-54. London; New York: Routledge.

Hess, David J. 2005. Technology-and Product-Oriented Movements: Approximating Social Movement Studies and Science and Technology Studies. Science, Technology, \& Human Values 30 (4): 515535.

Hess, David J. 1995. Science and Technology in a Multicultural World: The Cultural Politics of Facts and Artifacts. New York: Columbia Univ. Press.

Hoffman, Kelly M., Sophie Trawalter, Jordan R. Axt, and M. Norman Oliver. 2016. Racial Bias in Pain Assessment and Treatment Recommendations, and False Beliefs about Biological Differences between Blacks and Whites. Proceedings of the National Academy of Sciences of the United States of America 113 (16): 4296-4301. https://doi.org/10.1073/pnas.1516047113.

Kaplinsky, Raphael, Joanna Chataway, Norman Clark, Rebecca Hanlin, Dinar Kale, Lois Muraguri, Theo Papaioannou, P. Robbins, and Watu Wamae. 2009. Below the Radar: What Does Innovation in Emerging Economies Have to Offer Other Low-Income Economies? International Journal of Technology Management \& Sustainable Development 8 (3): 177-97.

Kleinman, Daniel Lee. 1998. Untangling Context: Understanding a University Laboratory in the Commercial World. Science, Technology, \& Human Values 23 (3):285-314.

Lehoux, Pascale, Geneviève Daudelin, Myriam Hivon, Fiona Alice Miller, and Jean-Louis Denis. 2014. How Do Values Shape Technology Design? An Exploration of What Makes the Pursuit of Health and Wealth Legitimate in Academic Spin-Offs. Sociology of Health \& Illness 36 (5): 738-55.

Lehoux, Pascale, Federico Roncarolo, Hudson Pacifico Silva, Antoine Boivin, Jean-Louis Denis, and Réjean Hébert. 2018. What Health System Challenges Should Responsible Innovation in Health Address? Insights From an International Scoping Review. International Journal of Health Policy and Management 0 (November). http://www.ijhpm.com/article_3572.html.

Pacifico Silva, Hudson, Pascale Lehoux, Fiona Alice Miller, and Jean-Louis Denis. 2018. Introducing Responsible Innovation in Health: A Policy-Oriented Framework. Health Research Policy and Systems 16 (1): 90. https://doi.org/10.1186/s12961-018-0362-5. 
Macnaghten, P., R. Owen, J. Stilgoe, B. Wynne, A. Azevedo, A. de Campos, J. Chilvers, et al. 2014. Responsible Innovation across Borders: Tensions, Paradoxes and Possibilities. Journal of Responsible Innovation 1 (2): 191-99. https://doi.org/10.1080/23299460.2014.922249.

Malkin, Robert A. 2007. Design of Health Care Technologies for the Developing World. Annual Review of Biomedical Engineering 9:567-87. https://doi.org/10.1146/annurev.bioeng.9.060906.151913.

Martin, Brian. 1981. The Scientific Straightjacket: The Power Structure of Science and the Suppression of Environmental Scholarship. Ecologist 11 (1): 33-43.

Metcalfe, J. Stanley, Andrew James, and Andrea Mina. 2005. Emergent Innovation Systems and the Delivery of Clinical Services: The Case of Intra-Ocular Lenses. Research Policy 34 (9): 1283304.

Neal, Homer A., Tobin L. Smith, and Jennifer B. McCormick. 2008. Beyond Sputnik : US Science Policy in the Twenty-First Century. Ann Arbor: University of Michigan Press.

Obama, Barack. State of the Union Address, February 12, 2013. https://www.forbes.com/sites/beltway/2013/02/12/full-text-president-obamas-2013-state-of-theunion-address/.

Oudshoorn, Nelly, Els Rommes, and Marcelle Stienstra. 2004. Configuring the User as Everybody: Gender and Design Cultures in Information and Communication Technologies. Science, Technology, \& Human Values 29 (1): 30-63. https://doi.org/10.1177/0162243903259190.

Papaioannou, T. 2014. How inclusive can innovation and development be in the twenty-first century? Innovation and Development, 4/2: 187-202. DOI: 10.1080/2157930X.2014.921355

Parthasarathy, Shobita. 2017. Patent Politics. Chicago: University of Chicago Press.

Peetz, David. 2015. An Institutional Analysis of the Growth of Executive Remuneration. Journal of Industrial Relations 57 (5): 707-25. https://doi.org/10.1177/0022185615590903.

Pereira, Maria do Mar. 2018. Boundary-Work That Does Not Work: Social Inequalities and the NonPerformativity of Scientific Boundary-Work. Science, Technology, \& Human Values, August, 0162243918795043. https://doi.org/10.1177/0162243918795043.

Pierce, Joy. 2009. Blind Inclusion: New Technology Designed for the Margins. Social Identities Journal for the Study of Race, Nation and Culture 15 (4): 525-36.

Prahalad, C.K., \& Hart, S.L. 2002. The fortune at the bottom of the pyramid. Strategy+business, First Quarter (26). Retrieved 15 November 2015, from http://www.strategybusiness.com/article/11518?gko=9a4ba

Read, Jen'nan Ghazal, and Bridget K. Gorman. 2010. Gender and Health Inequality. Annual Review of Sociology 36 (1): 371-86. https://doi.org/10.1146/annurev.soc.012809.102535.

Rafols, Ismael, Patrick van Zwanenberg, Molly Morgan, Paul Nightingale, and Adrian Smith. 2011. Missing Links in Nanomaterials Governance: Bringing Industrial Dynamics and Downstream Policies into View. The Journal of Technology Transfer 36 (6): 624-39. https://doi.org/10.1007/s10961-011-9208-9. 
Roth, Lorna. 2013. The Fade-Out of Shirley, a Once-Ultimate Norm: Colour Balance, Image Technologies, and Cognitive Equity. In The Melanin Millennium, 273-286. Springer.

Schoffer, Filemon. 2016. How Expiring Patents Are Ushering in the next Generation of 3D Printing. TechCrunch, May 15, 2016. http://social.techcrunch.com/2016/05/15/how-expiring-patents-areushering-in-the-next-generation-of-3d-printing/ .

Schot, Johan, and Arie Rip. 1997. The Past and Future of Constructive Technology Assessment. Technological Forecasting and Social Change, Technology Assessment: The End of OTA, 54 (2): 251-68. https://doi.org/10.1016/S0040-1625(96)00180-1.

Schuurbiers, Daan. 2011. What Happens in the Lab: Applying Midstream Modulation to Enhance Critical Reflection in the Laboratory. Science and Engineering Ethics 17 (4): 769-88. https://doi.org/10.1007/s11948-011-9317-8.

Settles, Isis H., NiCole T. Buchanan, and Kristie Dotson. 2018. Scrutinized but Not Recognized: (In)Visibility and Hypervisibility Experiences of Faculty of Color. Journal of Vocational Behavior, June. https://doi.org/10.1016/j.jvb.2018.06.003.

Shrum, Wesley. 2015. Development Aid: A New Course for STS. Science, Technology, \& Human Values 40 (3):445-55. https://doi.org/10.1177/0162243914562474.

Smith, Adrian, Mariano Fressoli, Dinesh Abrol, Elisa Arond, and Adrian Ely. 2016. Grassroots Innovation Movements. New York, NY: Routledge.

Smith, Adrian, and Andy Stirling. 2007. Moving Outside or Inside? Objectification and Reflexivity in the Governance of Socio-Technical Systems. Journal of Environmental Policy \& Planning 9 (3-4): 351-73. https://doi.org/10.1080/15239080701622873.

Stilgoe, Jack, Richard Owen, and Phil Macnaghten. 2013. Developing a Framework for Responsible Innovation. Research Policy 42 (9): 1568-80. https://doi.org/10.1016/j.respol.2013.05.008.

Stokes, D. 1997. Pasteur’s Quadrant. Washington D.C.: Brookings Institute.

Tomblin, David, Zachary Pirtle, Mahmud Farooque, David Sittenfeld, Erin Mahoney, Rick Worthington, Gretchen Gano, et al. 2017. Integrating Public Deliberation into Engineering Systems: Participatory Technology Assessment of NASA’s Asteroid Redirect Mission. Astropolitics 15 (2):141-66. https://doi.org/10.1080/14777622.2017.1340823.

Warren, Josephine. 2015. When Undone Science Stifles Innovation: The Case of the Tasmanian Devil Cancer. Prometheus 33 (3): 257-76. doi:10.1080/08109028.2016.1168202.

Whitley, Richard, Jochen Gläser, and Grit Laudel. 2018. The Impact of Changing Funding and Authority Relationships on Scientific Innovations. Minerva, January, 1-26. https://doi.org/10.1007/s11024018-9343-7.

Williams, Logan D. A. 2013. Three Models of Development: Community Ophthalmology NGOs and the Appropriate Technology Movement. Perspectives on Global Development and Technology 12 (4): 449-75. https://doi.org/10.1163/15691497-12341267. 
- 2017. Getting Undone Technology Done: Global Techno-Assemblage and the Value Chain of Invention. Science, Technology and Society 22 (1): 38-58.

https://doi.org/10.1177/0971721816682799.

- 2019. Eradicating Blindness: Global Health Innovation from South Asia. Singapore: Palgrave Macmillan. http://www.palgrave.com/9789811316241.

Williams, Logan D. A., and Thomas S. Woodson. 2012. The Future of Innovation Studies in Less Economically Developed Countries. Minerva 50 (2): 221-237.

Woodson, Thomas S., and Logan D. A. Williams. 2018. Stronger Together: Frameworks for Interrogating Inequality in Science and Technology Innovation. SSRN Scholarly Paper 3264086. Rochester, NY: Social Science Research Network. https://papers.ssrn.com/abstract=3264086.

Woodson, Thomas S. 2015. 3D Printing for Sustainable Industrial Transformation. Development 58 (4): 571-76. https://doi.org/10.1057/s41301-016-0044-y.

Woodson, Thomas, Julia Torres Alcantara, and Milena Silva do Nascimento. 2019. Is 3D Printing an Inclusive Innovation?: An Examination of 3D Printing in Brazil. Technovation, January. https://doi.org/10.1016/j.technovation.2018.12.001.

Winner, Langdon. 1980. Do Artifacts Have Politics? Daedalus, 109(1), 121-136. 